\title{
Maturity curve for estimating the in-place strength of high performance concrete
}

\author{
Aleksandra Mariak ${ }^{1, *}$, Marzena Kurpińska ${ }^{1}$, and Krzysztof Wilde ${ }^{1}$ \\ ${ }^{1}$ Gdańsk University of Technology, Faculty of Civil and Environmental Engineering, Poland
}

\begin{abstract}
The paper presents the maturity curve for estimating the in-place early-age compressive strength of concrete. The development of appropriate maturity curve is a complex process. It is important to correctly determine the datum temperature and activation energy, which can be obtained in mortar tests. This paper describes an investigation of the accuracy of the maturity method to estimate the strength when different way to rate constant and maturity function are analysed. High performance concrete used for construction of extradosed bridge was tested. The developed curve was implemented to predict the concrete strength at three construction stages, in summer, autumn and early spring.
\end{abstract}

\section{Introduction}

Monitoring of young concrete in connection with numerical analysis gives a practical knowledge about advancement of hydration process and opportunities for rationalization concrete works [1-2]. Thermal changes of hardening concrete over time are the basic parameter relatively easily measurable at the construction site. The issue of thermal aspect in young concrete are widely studied by many scientists [3-9].

Currently, the aim of the temperature registration of the hardening concrete is not only information about the significant temperature gradients, but also possibilities to estimation the compressive strength of concrete. So far, the traditional approach of measuring the strength was compression tests on laboratory and field-cured specimens. Nowadays, EN-13670 standards [10] recommend the appropriate maturity function to assessment of the strength development of in-place concrete. The existing measurement techniques [11-13] allow to monitor the young concrete properties and transfer obtained data to cooperating numerical models. There are also some difficulties in monitoring concrete, which changes the state of liquid into a solid e.g. equipment resistance to moisture, sensors failures as well as term of formwork removal. Regardless of these difficulties, monitoring of concrete is critically important to contractors and engineers who must decide when to safely allow construction loads or prestressing operations.

The concrete strength increases with the cement hydration process, and the rate of hydration reaction increases with temperature. This dependence indicates the possibility of describing the strength development as a function of the combined effects of time and temperature [14]. The above concept was defined as a maturity method for estimating the compressive strength of in-place concrete.

The maturity method assumes that samples of concrete mixture of the same maturity have similar strength, regardless of the combination of time and temperature yielding the maturity. The in situ strength is identified based on temperature and age history of inplace concrete and pre-determined calibration strengthmaturity relationship. The idea presented above seems clear and transparent, but developing a proper maturity function, is a complex process.

The paper shows procedure to determine maturity curve for high performance concrete $C 60 / 75$ class. This type of concrete was used to build the span of the largest extradosed bridge in Europe (Fig. 1). The technological project of the bridge construction assumed the division of the superstructure into assembly sections. The contractor planned to prestress every typical segment after 48 hours, so to achieve $60 \%$ strength for class $\mathrm{C} 60 / 75$, the designed concrete had to grow about $1 \mathrm{MPa} / \mathrm{h}$. It was necessary to use an alternative method to predict concrete strength based on the maturity function due to increase the confidence level of compressive strength as well as the considerable range and duration of the investment.

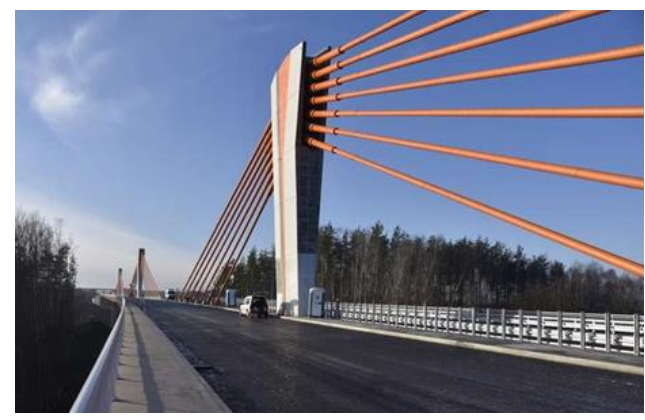

Fig. 1. View of the bridge [15] 


\section{Research methodology}

The procedure for estimating the concrete strength consists of two stages: laboratory work to determine the calibration curve and temperature measurements of a selected points in construction element [16]. ASTM C1074 [17] describes the basic procedure, however, as it turns out in practice, it is not so clear.

\subsection{Overview of laboratory procedure}

For laboratory tests, at least 15 cylindrical specimens of 150 x $300 \mathrm{~mm}$ must be prepared. Immediately after molding, two samples should be equipped with waterproof temperature sensors, placed inside the test specimen (within $\pm 15 \mathrm{~mm}$ of the centers). The concrete temperature should be measured every 30 minutes or less for the first 48 hours. Thereafter time interval may be equal to one hour or less. All samples should be stored in a moist room (relative humidity $\geq 95 \%$ ) or in a water bath under standard laboratory conditions at $20 \pm 2{ }^{\circ} \mathrm{C}$. On the others 13 cylindrical specimens, compression tests should be performed at ages of 1, 3, 7, 14 and 28 days. For concrete mixtures with rapid strength development, test should begin in other terms, that they will provide approximately equal increments of strength gain between test ages. The standard also allows to carry out the same test procedure for cubic specimens [17].

The measured temperature history allows to calculate maturity index according to equation (1) or (2):

$$
\begin{gathered}
M(t)=\sum_{0}^{t}\left(T-T_{o}\right) \Delta t, \\
t_{e}=\sum e^{-Q\left(\frac{1}{T}-\frac{1}{T_{s}}\right)} \Delta t,
\end{gathered}
$$

where $M(t)$ means temperature-time factor $\left[{ }^{\circ} \mathrm{C}-\mathrm{h}\right], t$ age $[\mathrm{h}], \Delta t$ time interval $[\mathrm{h}], T$ average concrete temperature during time interval $\Delta t\left[{ }^{\circ} \mathrm{C}\right], T_{o}$ datum temperature $\left[{ }^{\circ} \mathrm{C}\right], t_{e}$ equivalent age $[\mathrm{h}], T_{s}$ specified temperature $\left[{ }^{\circ} \mathrm{C}\right]$ and $Q[\mathrm{~K}]$ activation energy divided by the gas constant.

The information about maturity index and corresponding compressive strength enables to plot strength-maturity relationship to be used for estimating the strength of the concrete mixture cured under other temperature conditions. The procedure presented above requires the definition of constants $T_{o}$ and $Q$ as well as an approximation of the data through best-fit curve. There are many suggestions in the literature to determine the activation energy depending on the type of cement or the hardening temperature, but all of these equations present different and, importantly, divergent conclusions regarding to $Q$ value $[6,18,19]$. In order to ensure the maximum accuracy of strength estimation, the appropriate values of $T_{o}$ or $Q$ may be determined experimentally by testing mortar samples. If we want to reliably estimate the concrete strength on the construction site, remember that each concrete mixture is different.

The mortar testing required to prepare three sets of $50 \mathrm{~mm}$ cubes, with 18 cubes per set. Proportion of mortar mixture shall have the same water-cement ratio and the same amount of additives/admixtures of the concrete under investigation. The samples are maintained in water bath at three different temperatures: $T_{1}, T_{2}, T_{3}$. These temperatures correspond to the maximum, average and minimum concrete temperatures expected in construction site during the period when strength is to be estimated.

Compression tests are carried out on three cubes from every bath when age is approximately twice of the final setting time or when the strength is about $4 \mathrm{MPa}$ (if final setting time was not measured). For example, if the time of the first test was $6 \mathrm{~h}$, another tests would be carried out at $12 \mathrm{~h}$ and $1,2,4,8$ days.

The strength data obtained for mortar cubes hardening at different temperatures is analysed to determine the relationship between the rate constant $k$ and the curing temperature. The ASTM standard [17] gives three procedures to calculate rate constant $k$. If linear regression of reciprocal time on reciprocal strength is used, it can be apply procedure A1.1.7 or A1.1.8.2. For nonlinear analysis procedure A1.1.8.1 is recommended. The result of the calculation is determination of datum temperature $T_{o}$ and constant $Q$.

It is well-known that the curing temperature has a significant influence on the strength gain. It occurs that a low temperature causes a decrease in long-term strength, but this is not the rule. As Kjellsen's and Detwiler's research shows, specimens cured at isothermal temperatures of 5 or $12,5^{\circ} \mathrm{C}$ achieved higher long-term strength than the specimens cured at 20,35 and $50{ }^{\circ} \mathrm{C}$ (Fig. 2). Carino [21] termed this loss of strength due to curing at high temperatures the "crossover effect."

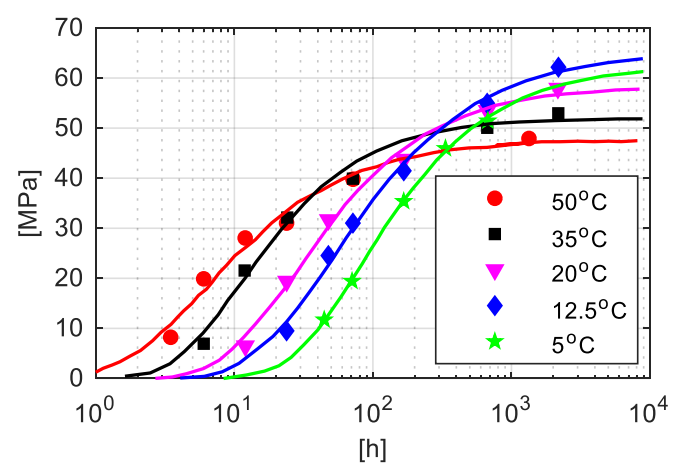

Fig. 2. Mortar compressive strength [22]

\subsection{Strength-age relationships}

The basic parameter for the appropriate maturity function of a concrete mixture is rate constant $k$ with the curing temperature. As mentioned previously, linear regression can be used to analyze strength - age data, but it is also possible to apply three types of function : the hyperbolic, the logarithmic and the exponential, for the data fitting. 
Freiesleben Hansen and Pedersen [23] proposed an exponential formulation to characterize the s-shaped development of the compressive strength under isothermal conditions:

$$
S=S_{u} \cdot \exp [-(\tau / t)]^{\alpha},
$$

where $S$ means compressive strength at time $t$ [MPa], $S_{u}$ ultimate compressive strength [MPa], $t$ age [day], $\tau$ time constant [day], and $\alpha$ shape constant [-]. This equation enables to model strength development during the setting period, the period of strength gain and it is also asymptotic to a limiting strength [7]. The regression coefficient $\tau$ represents the age, when strength has reached approximately $0,37 S_{u}$, thus its reciprocal $(1 / \tau)$ is the rate constant $k$ [1/day]. The shape constant $\alpha$ affects the slope of the curve during acceleratory period and also the rate with which the strength reaches the ultimate strength [7, 21].

Another model that has been published is the hyperbolic strength-age relationship [14]:

$$
S=S_{u} \cdot \frac{k \cdot\left(t-t_{0}\right)}{1+k \cdot\left(t-t_{0}\right)} .
$$

In this formula, $t_{0}$ represents age in which the strength development begins, therefore the equation (4) does not take into account the setting period. The parameters $S_{u}$, $k, t_{0}$ are obtained by the least squares method on the way of approximation strength versus age data. The limiting strength $S_{u}$ is the asymptotic value for the hyperbolic function, but it does not necessarily correctly represent the actual long-term strength of the concrete. In equation (4) the rate constant $k$ has following property: reciprocal $1 / k$ means time $t$, when strength $S$ equals $50 \%$ of the ultimate strength $S_{u}$, but that time is beyond $t_{0}$ [14]. The appendix of ASTM C1074 [17] uses equation (4) to determine datum temperature and activation energy.

A similar function to the model (4) was presented by Knudsen [24] and Geiker [25]. Geiker noted that equation (4) gives unsatisfactory results for some cementitious systems and proposed an equation in the form:

$$
S=S_{u} \cdot \frac{\sqrt{k \cdot\left(t-t_{0}\right)}}{1+\sqrt{k \cdot\left(t-t_{0}\right)}}
$$

Knudsen [24] explained the differences between equation (4) and (5) in relation to cement hydration kinetics. Equation (4) is based on linear kinetics and equation (5) is based on parabolic kinetics. It means that in the first case the degree of cement hydration is a linear function of time and the rate constant while the second approach means that the degree of hydration is a function of the square root of time and the rate constant. Therefore, eq. (4) describes a linear hyperbolic model, and eq. (5) a parabolic hyperbolic model.

\subsection{Strength-maturity relationships}

Equations (3), (4), (5) expressed in the function of the maturity index can be used to describe the strengthmaturity relationship but the literature also presents other maturity functions.

One of the popular relationships is the Plowman's logarithmic equation [26]:

$$
S=a+b \cdot \log _{10}\left(t_{e}\right)
$$

where $a$ means regression coefficient equals strength for equivalent age $t_{e}=1$ and $b$ is the slope of line. This approach is popular and practiced by engineers due to its simplicity. When the log scale is used, eq. (6) is drawn as straight line. This function predicts a strength increase as maturity increases, but there is no limiting strength.

An alternative to the Plowman's proposition is the hyperbolic function presented by China [27]:

$$
S=\frac{t_{e}}{1 / A_{a}+t_{e} / S_{u}}
$$

where $A_{a}$ is initial slope of line.

For approximation of experimental data, authors also proposed a power function in the form of:

$$
S=c \cdot t_{e}^{d}+r
$$

as well as exponential formula as following:

$$
S=g \cdot \exp \left(h \cdot t_{e}\right)+l \cdot \exp \left(p \cdot t_{e}\right) .
$$

The parameters $c, d, r, g, h, l$, and $p$ occurring in the equation (8) and (9) are regression coefficient.

\section{Experimental investigations}

The experimental study was focused to determine the best fit strength-maturity curve dedicated to predict the development of compressive strength, $\mathrm{C} 60 / 75$ class. The laboratory tests were carried out on 54 mortar cubes of $50 / 50 / 50 \mathrm{~mm}, 20$ cylindrical samples $(150 / 300 \mathrm{~mm})$ and 26 cubic specimens $(150 \mathrm{~mm})$ made of mixture presented in Table 1. The chemical and physical compositions of cement are mentioned in Table 2.

The scope of research included compression tests, elastic modulus measurements and registration of temperature changes in concrete samples. Before the specimens were moulded, the basic parameters of concrete mixture (consistency, air content and apparent density) were identified.

Temperature measurements were carried out using self-developed sensor system. The electronic device recognizes the 1-wire sensors on the basis of 16 digital serial numbers. The developed system enables to measure temperature in range of $-55^{\circ} \mathrm{C}$ to $+125^{\circ} \mathrm{C}$ with an accuracy of $\pm 0,5^{\circ} \mathrm{C}$. 
Table 1. Overview of mixture proportions

\begin{tabular}{|l|c|}
\hline Component & {$\left[\mathbf{k g} / \mathbf{m}^{3}\right]$} \\
\hline CEM I 52,5 N SR3 NA & 440 \\
\hline Water & 143 \\
\hline Silica sand 0/2 mm & 632 \\
\hline Basalt grit 2/8 mm & 498 \\
\hline Basalt grit 8/16 mm & 785 \\
\hline Plasticizer $(1,95 \%$ m. c.) & 8,49 \\
\hline
\end{tabular}

Table 2. Chemical and physical properties of cement

\begin{tabular}{|l|c|}
\hline Component & CEM I 52,5 N SR3 NA \\
\hline $\mathrm{SO}_{3}$ & $2,6 \%$ \\
\hline $\mathrm{Cl}^{-}$ & $0,07 \%$ \\
\hline $\mathrm{Na}_{2} \mathrm{O}$ & $0,5 \%$ \\
\hline $\mathrm{Al}_{2} \mathrm{O}_{3}$ & $3,9 \%$ \\
\hline $\mathrm{C}_{3} \mathrm{~A}$ & $1,8 \%$ \\
\hline $\mathrm{C}_{3} \mathrm{AF}+2 \mathrm{C}_{3} \mathrm{~A}$ & $18,9 \%$ \\
\hline Density & $3,2 \mathrm{~g} / \mathrm{cm}^{3}$ \\
\hline Blain area & $3789 \mathrm{~g} / \mathrm{cm}^{2}$ \\
\hline LOI & $1,1 \%$ \\
\hline
\end{tabular}

Concrete mix design is required to achieve target strength in structures. There are three phases in the development of a concrete mixture: specifying, designing and proportioning. The assumption for highperformance concrete was to reach a minimum of $47 \mathrm{MPa}$ after 48 hours hardening. Other requirements for the mixture were: the water-cement ratio $<0,34$ exposure class XC4, XD1 and XF2, consistency S4 in place, absorbability $<5 \%$, water tightness W8, frost resistance F150, air content $4,0-6,0 \%$ in place. In addition, concrete should have good pumpability and workability.

\subsection{Mortar testing}

The mortar cubes were cured at isothermal temperatures: $T_{1}=5^{\circ} \mathrm{C}, T_{2}=24^{\circ} \mathrm{C}$ and $T_{3}=35^{\circ} \mathrm{C}$ by maintaining them in controlled temperature water baths. As the normal temperature, the air laboratory temperature equals $24{ }^{\circ} \mathrm{C}$ was assumed. Strength measurements for cubes stored at $5{ }^{\circ} \mathrm{C}$ were carried out after $2,3,4,5,7$ and 14 days, for samples cured at $24^{\circ} \mathrm{C}$ and $35^{\circ} \mathrm{C}$ after $1,2,3,5,7$ and 14 days (Fig. 3). Every set of three cubes were tested at six different ages. The terms of research depended on rapid of strength increase (high at $24,35^{\circ} \mathrm{C}$ and low at $5^{\circ} \mathrm{C}$ ). According to the guidelines of ASTM C1074 [17], the compression test should be done at the age of twice of final setting time or for minimum cube strength equals $4 \mathrm{MPa}$. This recommendation requires different dates of research for each set of samples. This procedure has been simplified and fixed terms have been adopted regardless of the curing temperature.

The strength results for mortar are shown in Fig. 4. What's interesting, samples hardening at $35^{\circ} \mathrm{C}$, after $8 \mathrm{~h}$ still exhibited plastic features, and after $24 \mathrm{~h}$ have already reached an average strength of $47,3 \mathrm{MPa}$. The rapid hydration of mortar samples hardening at $35^{\circ} \mathrm{C}$ is incomparably higher than at $5^{\circ} \mathrm{C}$ accepted as minimum value for concrete cast in place. The cubes at $5{ }^{\circ} \mathrm{C}$ after 2 days reach an average strength of $6,9 \mathrm{MPa}$, and specimens cured at $35^{\circ} \mathrm{C}$ after 1 day reach $47,3 \mathrm{MPa}$. The highest strength after 14 days noted for cubes hardening at "normal" temperature $\left(24^{\circ} \mathrm{C}\right)$, slightly lower at $35^{\circ} \mathrm{C}$ and lowest at $5^{\circ} \mathrm{C}$, reaching 90,1, 88,7 and $84,1 \mathrm{MPa}$, respectively.
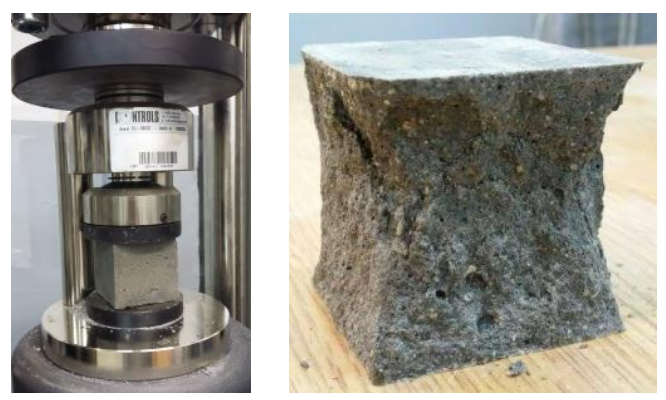

Fig. 3. Mortar compression test

To identify $T_{o}$ and $Q$, the rate constant $k$ according to linear (appendix A1.1.7 and A1.1.1.8.2 [17]) and nonlinear regression were analysed. For linear analysis, the calculations were done twice, at first time on raw data and the second time after omitting the earliest-age data point, which generated nonlinearity effect. The calculation results are summarized in Table 3 .

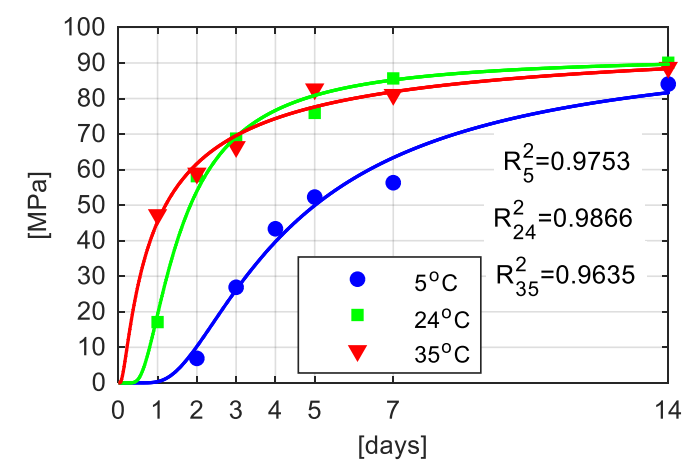

Fig. 4. Compressive strength for mortar cubes cured at three temperatures: measured data and exponential regression eq. (3)

Table 3. Regression analysis

\begin{tabular}{|c|c|c|c|c|c|c|}
\hline$\stackrel{\infty}{\stackrel{0}{0}}$ & $\begin{array}{c}T \\
{\left[{ }^{\circ} \mathrm{C}\right]}\end{array}$ & $\begin{array}{c}k \\
{[1 / \text { day }]}\end{array}$ & $\begin{array}{c}T_{o} \\
{\left[{ }^{\circ} \mathrm{C}\right]}\end{array}$ & $\begin{array}{c}R_{T o}{ }^{2} \\
{[-]}\end{array}$ & $\begin{array}{c}Q \\
{[\mathrm{~K}]}\end{array}$ & $\begin{array}{c}R_{Q}{ }^{2} \\
{[-]}\end{array}$ \\
\hline \multirow{3}{*}{ 总 } & 5 & 0,334 & \multirow{3}{*}{$-1,3$} & \multirow{3}{*}{0,9792} & \multirow{3}{*}{4766} & \multirow{3}{*}{0,9984} \\
\hline & 24 & 1,052 & & & & \\
\hline & 35 & 1,750 & & & & \\
\hline \multirow{3}{*}{ 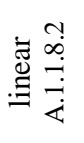 } & 5 & 0,162 & \multirow{3}{*}{$-0,1$} & \multirow{3}{*}{0,9961} & \multirow{3}{*}{5452} & \multirow{3}{*}{0,9863} \\
\hline & 24 & 0,676 & & & & \\
\hline & 35 & 1,050 & & & & \\
\hline \multirow{3}{*}{ 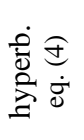 } & 5 & 0,254 & \multirow{3}{*}{$-1,6$} & \multirow{3}{*}{0,9711} & \multirow{3}{*}{4606} & \multirow{3}{*}{0,9998} \\
\hline & 24 & 0,747 & & & & \\
\hline & 35 & 1,272 & & & & \\
\hline \multirow{3}{*}{ 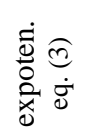 } & 5 & 0,273 & \multirow{3}{*}{$-1,0$} & \multirow{3}{*}{0,9431} & \multirow{3}{*}{4620} & \multirow{3}{*}{0,9981} \\
\hline & 24 & 0,749 & & & & \\
\hline & 35 & 1,397 & & & & \\
\hline
\end{tabular}


It has been found that the similar value of $k$ and $Q$ provide only a nonlinear analysis. As a reliable exponential regression results were assumed. For the considered mortar, the datum temperature which corresponds to the significant slowdown of the hydration process is $-1,0^{\circ} \mathrm{C}$ (Fig. 5a). The energy needed to initiate a hydration reaction equals the tangent of the slope of line ( $Q=4620 \mathrm{~K}$, Fig. 5b). Therefore, the equivalent age should be defined as:

$$
t_{e}=\sum e^{-4620\left(\frac{1}{T}-\frac{1}{273.15+24}\right)} \Delta t .
$$

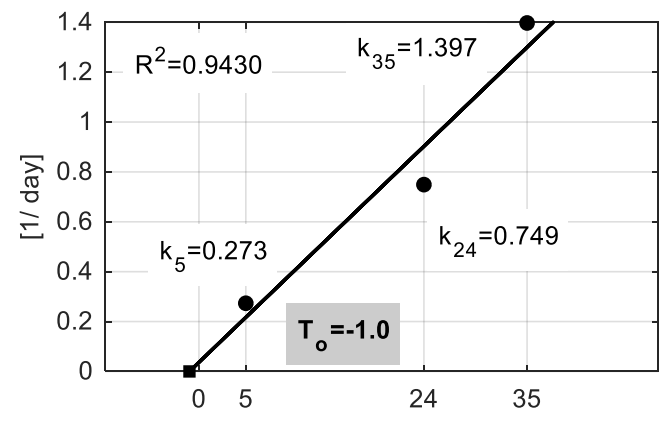

a)

$\left[{ }^{\circ} \mathrm{C}\right]$

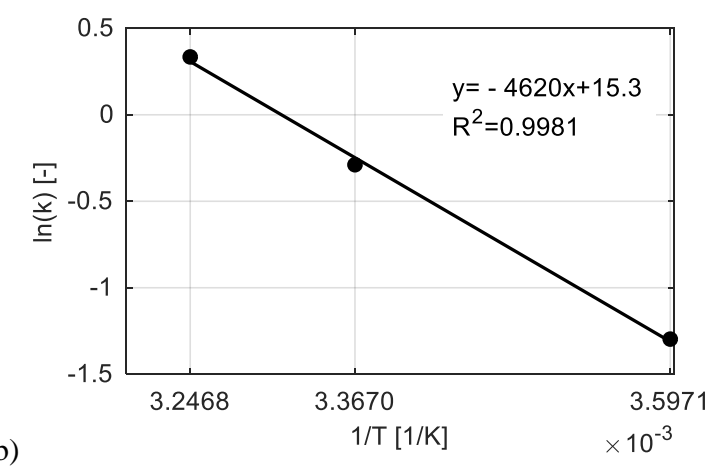

Fig. 5. a) $k$ values versus curing temperature for determining $T_{o}$, b) natural logarithm of $k$-values versus the inverse absolute temperature for determining $Q$

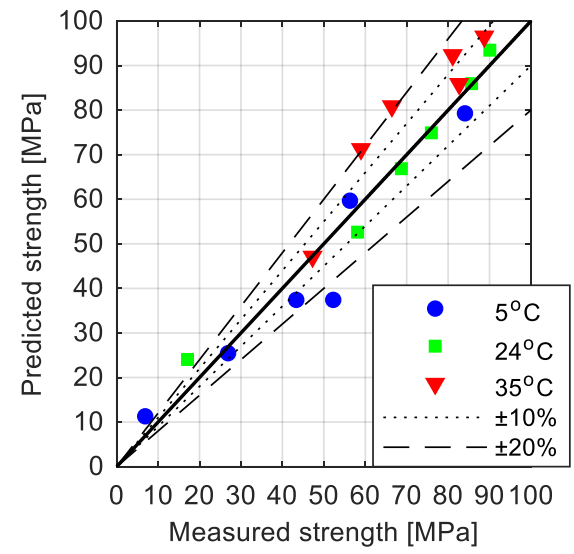

Fig. 6. Estimated strength versus measured strength with equivalent age maturity method (exponential model - eq. (3))

In order to compare the strengths as estimated by the equivalent age maturity method with the measured strengths at 5 and $35^{\circ} \mathrm{C}$, Fig. 6 has been plotted. All strengths are estimated through the use of the exponential strength-maturity relationship (eq. (3)) and with the equivalent age (eq. (10)). When the hyperbolic strength-maturity function is used, the accuracy is approximately the same. It should be noted the test points achieved at $24{ }^{\circ} \mathrm{C}$ are expected to fall close to the $45^{\circ}$ line. Both approaches predict the strength in hardening samples at 5 and $35{ }^{\circ} \mathrm{C}$ with an error range of $20 \%$. We can observe overestimation by maturity method for cubes curing at $35^{\circ} \mathrm{C}$ and underestimation at $5^{\circ} \mathrm{C}$.

\subsection{Concrete testing}

The maturity curve for considered concrete on cubic and cylindrical samples was determined. The compression tests were carried out on 18 cylinders and 24 cubes. In parallel, the concrete temperature for two samples of each type was measured. A test result is the average of at least two standard-cured strength specimens (Fig. 7). The cubic samples were tested after $24 \mathrm{~h}$, and the cylindrical one after $28 \mathrm{~h}$, which resulted similar strengths for both types of samples (34,6 and 36,5 MPa). At 28 days, we have a strength of $85,3 \mathrm{MPa}$ and of $66,5 \mathrm{MPa}$ for cubes and cylinders, respectively. The concrete class $\mathrm{C} 60 / 75$ has been fulfilled.

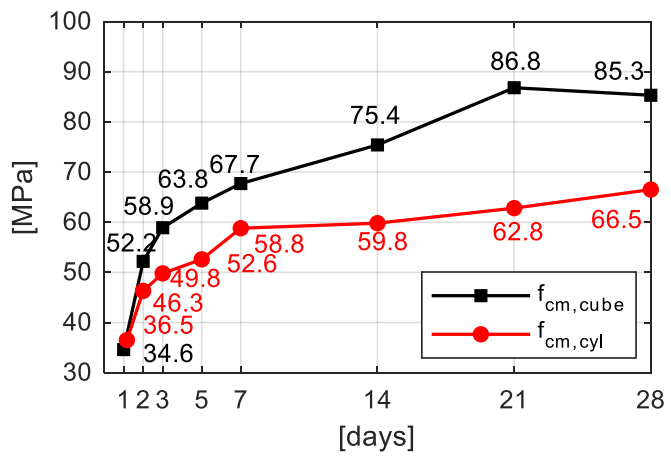

Fig. 7. Cylindrical and cubic compressive strength of concrete

Fig. 8 presents the temperature evolution of concrete during first 5 days $(120 \mathrm{~h})$. The initial temperature of concrete mixture equals $22,9^{\circ} \mathrm{C}$. The cement hydration is strongly exothermic reaction, so after 19 hours the maximum value of temperature were registered. For cylindrical samples, the average maximum temperature $\left(27,6^{\circ} \mathrm{C}\right)$ is higher by $3,0^{\circ} \mathrm{C}$, and for cubic samples $\left(29,2^{\circ} \mathrm{C}\right)$ by $4,6^{\circ} \mathrm{C}$ in relation to the water temperature $\left(24,6^{\circ} \mathrm{C}\right)$

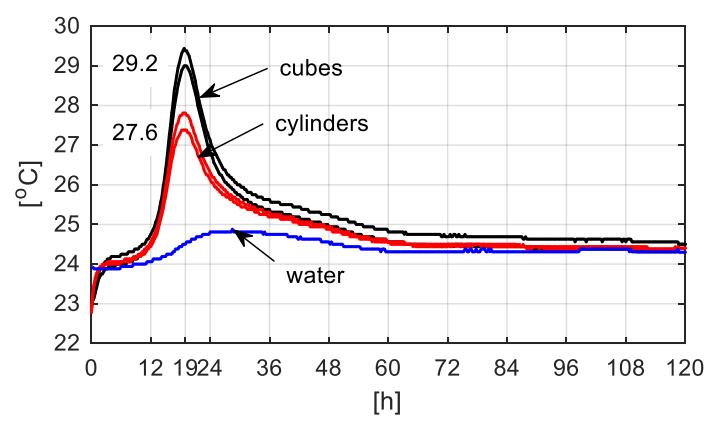

Fig. 8. Temperature evolution of concrete specimens 
Equation number (10), thermal history of concrete samples and information about obtained compressive strengths provide to the researcher a complete data set for the development of maturity curve. In the case under consideration data regression using the formulas (3), (4), (6), (7), (8) and (9) was performed (Fig. 9). The best fit function, suitable in the entire range was the power equation (8). In all cases, the value of the determination coefficient $R^{2}$ is greater than 0,97 (Fig. 10, Fig. 11).

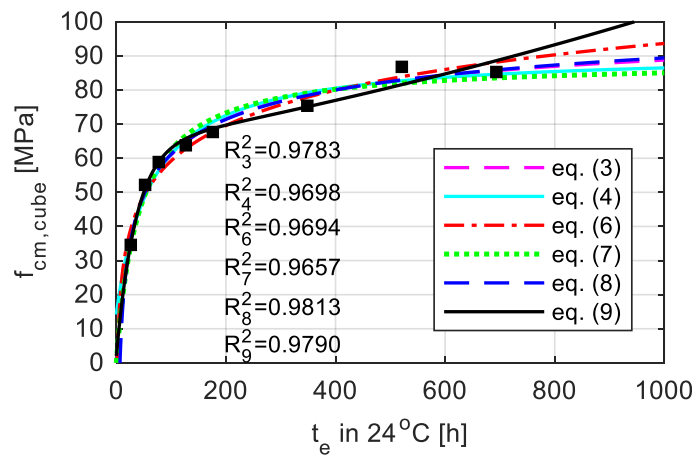

Fig. 9. Regression analysis of cubic strength

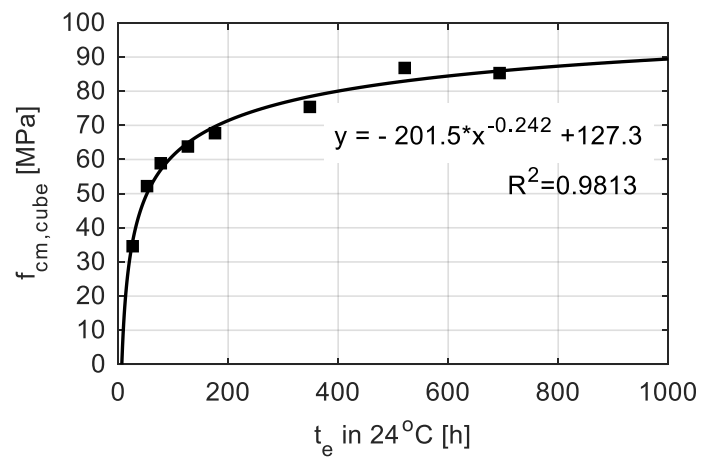

Fig. 10. Maturity curve related to cubic strength

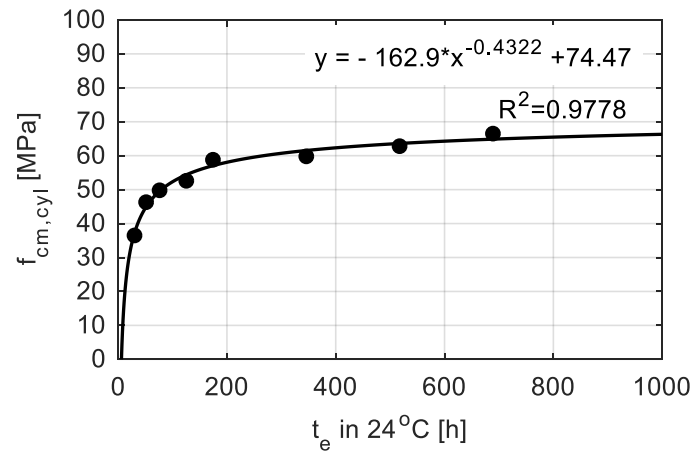

Fig. 11. Maturity curve related to cylindrical strength

\section{Summary}

The strength gain over time is closely related to the temperature in the early age, which has been proven in the mortar tests hardening at 5, 24 and $35^{\circ} \mathrm{C}$. After 14 days, the cubes strength at $5^{\circ} \mathrm{C}$ was about $7 \%$ lower than the others and no crossover effect was observed. For relevant mortar the rate constant $k$ was reliable only for nonlinear analysis. If the relationship between reciprocal time and reciprocal strength is slightly nonlinear due to early-age effect, then the error can be quite large. Thus, linear regression is not satisfied. Finally, the activation energy for the considered concrete was $38400 \mathrm{~mol} / \mathrm{K}$.

The purpose of this study was estimation early-age concrete strength required to presstresing superstructure elements (45 MPa for cube strength and $36 \mathrm{MPa}$ for cylindrical strength). The considered concrete was characterized rapid strength development, thus, in this case the initial phase of the maturity curve was the most important. To describe the strength-maturity relationship of $C 60 / 75$ concrete, the power equation proposed by the authors was used. This formula was true throughout the entire time, for low and high value of maturity index. The power curve also gives the closest solution to the Freiesleben's curve. The Plowman's logarithm curve and the proposed exponential curve should be used with caution, because it does not provide correct results in the final range. Taking into account a wide range of additives, admixtures and various types of cement, every concrete requires an individual approach [28-30] An interesting issue would be the analysis of lightweight concrete [31-33] using the maturity method.

\section{References}

1. J. Chróścielewski, A. Mariak, A. Sabik, B. Meronk, K. Wilde, Adv. Sci. Technol. Res. J., 10, 254-262, (2016)

2. A. Mariak, J. Chróścielewski, K. Wilde, Shell Structures: Theory and Applications, 4, 557-560 (2018)

3. S. G. Bergström, Mag. Concr. Res., 5, 61-66 (1953)

4. N.J. Carino, Temperature Effects on the StrengthMaturity Relation of Mortar, National Bureau of Standards, (1981)

5. B. Klemczak, Modelowanie efektów termicznowilgotnościowych $i$ mechanicznych $w$ betonowych konstrukcjach masywnych. Wydawnictwo Politechniki Śląskiej, Gliwice, in Polish, (2008)

6. J. E. Jonasson, P. Groth, H. Hedlund, International Symposium Thermal Cracking in Concrete at Early Ages, Munich, 45-52 (1994)

7. P. Witakowski, Termodynamiczna teoria dojrzewania. Zastosowanie do konstrukcji masywnych $z$ betonu. Politechnika Krakowska, Zeszyt Naukowy nr 1, Kraków, in Polish, (1998)

8. M. Kaszyńska, S. Skibicki, 3rd World Multidisciplinary Earth Sciences Symposium (WMESS), 95 (2017)

9. B. Klemczak, K. Flaga, A. Knoppik-Wrobel, ACME, 17, 1, 75-95 (2017)

10. EN 13670: 2011 Execution of concrete structures

11. M. Miśkiewicz, Ł. Pyrzowski, K. Wilde, O. Mitrosz, Polish Maritime Research, 24, 149-155 (2017)

12. Ł. Pyrzowski, M. Miśkiewicz, J. Chróścielewski, Polish Maritime Research, 24, 182-187 (2017) 
13. A. Mariak, M. Miśkiewicz, B. Meronk, Ł. Pyrzowski, K. Wilde, Advances in Mechanics: Theoretical, Computational and Interdisciplinary Issues, 383-387 (2016)

14. N.J. Carino, H.S. Lew, Structures Congress \& Exposition, (2001)

15. Dziennik Ostródzki: https://ostroda.wm.pl

16. Mariak A., Wilde K., Monografie Technologii Betonu, 611-626, in Polish, (2016)

17. ASTM C1074-11, Standard Practice for Estimating Concrete Strength by the Maturity Method, (2011)

18. P. Freiesleben Hansen, E. J. Pedersen, Måleinstrument til kontrol af betons haerdning. J. Nord. Concrete Fed., in Swedish, 1, 21-25, (1977)

19. R. C. Tank, N. J. Carino, ACI Materials Journal, 88, 1, 74-83 (1991)

20. N. J. Carino, Journal of Cement, Concrete and Aggregates, 6, 2, 61-73 (1984)

21. N. J. Carino, The maturity method. CRC handbook on nondestructive testing of concrete, 101-146 (1991)

22. K. O. Kjellsen, R. J. Detwiler, ACI Mater. J., 90, 3, 220-227 (1993)

23. P. Freiesleben Hansen, E. J. Pedersen, Curing of concrete structures. Draft DEB - Guide to durable concrete structures. Appendix 1. Comite EuroInternational du Beton, Switzerland (1985)

24. T. Knudsen, 7th International Congress on the Chemistry of Cement, 170-175 (1980)

25. M. Geiker, Studies of Portland Cement Hydration by Measurements of Chemical Shrinkage and Systematic Evaluation of Hydration Curves by Means of the Dispersion Model (1983)

26. J. M Plowman., Magazine of Concrete Research, 8, 22, 13-22 (1956)

27. F. K. Chin, ACI Journal Proceedings, 68, 3, 196203 (1971)

28. P. Dybel, K. Furtak, ACME, 17, 4, 795-805, (2017)

29. E. Horszczaruk, P. Sikora, K. Cendrowski, E. Mijowska, Construction and Building Materials, 137, 420-431 (2017)

30. P. Sikora, E. Horszczaruk, K. Skoczylas, T. Rucinska, Creative Construction Conference 2017, Procedia Engineering 196, 159 - 166, 2017.

31. M. Kurpińska, T. Ferenc, Shell Structures: Theory and Applications, 4, 549-552 (2018)

32. M. Kurpińska, T. Ferenc, II International Conference of Computational Methods in Engineering Science, CMES, (2017)

33. M. Kaszyńska, A. Zieliński, 7th Scientific-Technical Conference Material Problems in Civil Engineering (MATBUD), Procedia Engineering, 108, 608-615 (2015) 